\title{
Retraction Note to: Impact of beauty and charm H1-ZEUS combined measurements on PDFs and determination of the strong coupling
}

The Publishers

Società Italiana di Fisica and Springer-Verlag GmbH Germany, part of Springer Nature

Original article: Eur. Phys. J. A (2017) 53: 220, DOI: 10.1140/epja/i2017-12405-4

Received: 25 July 2018

Published online: 6 August 2018

(C) Società Italiana di Fisica / Springer-Verlag GmbH Germany, part of Springer Nature, 2018

The article Impact of beauty and charm H1-ZEUS combined measurements on PDFs and determination of the strong coupling has been retracted at the request of the Editor-in-Chief. The article substantially overlaps with the following article: Impact of charm H1-ZEUS combined data and determination of the strong coupling in two different schemes (Chin. Phys. C 41, 113104 (2017)). 